\title{
PSYCHONOMIC SOCIETY MEMBERSHIP STATEMENT
}

The membership committee is charged with the selection of applicants who are qualified to conduct and to supervise scientific research in psychology or allied sciences. As determined by the bylaws, the policy stimpulates a PhD degree or the equivalent, as well as publication of significant research other than the doctoral dissertation. In attempting to determine whether applicants meet the membership requirements, the committee examines their vitae looking for evidence of an independent research program. Typically, we find that 2-4 postdoctoral years are required to accumulate evidence of an ability to conduct research on an independent basis and supervise research outside of the situation in which one was trained. We usually look for publications that move beyond the doctoral work and appear to be substantial, judging from such criteria as length, title and whether the articles appear in journals refereed by experts in the field. Final decisions about a candidate are often difficult. Each member of the three-person committee votes: 0, 1, or 2, depending upon how fully the member feels the candidate meets the requirements. A total of 4 points is needed for membership in the Society. Candidates not approved for membership may apply again when their credentials are stronger.

(Applications for membership, as well as dues and journal information, may be obtained from Professor James Voss, Learning Research and Development Center, University of Pittsburgh, Pittsburgh, Pennsylvania 15260.) 